\title{
Comment on Oguz et al.: A new classification and guide for surgical treatment of spinal tuberculosis
}

\author{
Sumant Samuel
}

Received: 11 December 2009 /Accepted: 11 December 2009/Published online: 4 February 2010

(C) Springer-Verlag 2010

\section{Dear Editor,}

In their article, Oguz et al. have proposed a classification of spinal tuberculosis as a guide to surgical management [4]. They were able to classify all their 76 cases with this classification system retrospectively. I would like to make the following observations in this regard.

The usual presentation of spinal tuberculosis is paradiscal involvement of two adjacent vertebrae, the intervening disc and, frequently, a paravertebral or psoas abscess. This classical picture is readily identifiable and presents no diagnostic difficulties. Posterior spinal tuberculosis, where there is isolated involvement of the neural arch, is a rare manifestation of spinal tuberculosis $[1,2]$. It is the most common of the different atypical presentations and its incidence has been variously reported to be up to $10 \%$ [1]. It is of interest, therefore, that there are no cases of posterior spinal tuberculosis in their large series of patients. It must also be mentioned here that posterior spinal tuberculosis is more prevalent in certain areas, most reports of these originating from the Indian subcontinent [5].

Posterior spinal tuberculosis has many features that are different from the typical paradiscal tuberculosis. Foremost among these is the delay in diagnosis due to atypical radiographic features. Second, cases of isolated posterior spinal tuberculosis do not present with a kyphotic deformity as kyphosis is due to loss of stability of the anterior elements. Another striking feature is the early and high incidence of neurological complications [1].

\footnotetext{
S. Samuel $(\bowtie)$

Department of Orthopedics, Christian Medical College,

Vellore, Tamil Nadu, India

e-mail: sumantsamuel@gmail.com
}

But perhaps the most striking difference arises in the treatment of posterior spinal tuberculosis. While anterolateral decompression is advocated for the classical disease, decompression for posterior spinal tuberculosis with neurological deficits and cauda equina is by laminectomy. This is because cord compression is from the dorsal aspect, unlike the more common picture of pressure from the anterior aspect seen with disease of the vertebral bodies. Neural arch tuberculosis with deficits is therefore a rare indication for posterior decompression (laminectomy), which otherwise is contraindicated in the presence of anterior disease $[1,3]$.

Posterior spinal tuberculosis does not find a place in the classification proposed by the authors and its treatment by laminectomy is also not brought out. In this regard, the classification proposed by Mehta and Bhojraj seems more inclusive [3]. They have grouped posterior spinal tuberculosis as a separate category requiring posterior decompression. Though described for the thoracic vertebrae, its use can be extended to the lumbar vertebrae as well with modifications.

\section{References}

1. Babhulkar SS, Tayade WB, Babhulkar SK (1984) Atypical spinal tuberculosis. J Bone Jt Surg [Br] 66:239-242

2. Kumar K (1985) A clinical study classification of posterior spinal tuberculosis. Int Orthop 9:147-152

3. Mehta JS, Bhojraj SY (2001) Tuberculosis of the thoracic spine. A classification based on the selection of surgical strategies. J Bone Jt Surg [Br] 83:859-863

4. Oguz E, Sehirlioglu A, Altinmakas M, Ozturk C, Komurcu M, Solakoglu C, Vaccaro AR (2008) A new classification and guide for surgical treatment of spinal tuberculosis. Int Orthop 32:127-133

5. Tibau R, Fuster S, Auleda J, Ubierna MT, Roca J, Alemany X, Ramon R (1994) Tuberculosis of the neural arch: a report of four cases. Int Orthop 18(6):119-121 